\title{
Direct Electrochemistry of Eugenol at a Glassy Carbon Electrode Modified with Electrochemically Reduced Graphene Oxide
}

Shijie Wang ${ }^{1}$, Ting Zhang ${ }^{1}$, Zhe Wang ${ }^{1}$, Dong Wang ${ }^{1}$, Zhao Wang ${ }^{1}$, Mojie Sun ${ }^{1 *}$, Xiaochen Song ${ }^{2}$, Hong Liu $^{3}$

${ }^{1}$ School of Chemical Engineering, Northeast Electric Power University, 169 ${ }^{\#}$ Changchun Road, Chuanying District, Jilin 132012, China

${ }^{2}$ School of Mechanical Engineering, Northeast Electric Power University, 169\# Changchun Road, Chuanying District, Jilin 132012, China

${ }^{3}$ Jilin Environmental Monitoring Station, 27* Songjiang Road, Changyi District, Jilin 132012, China

*E-mail: $\underline{\text { smoj@neepu.edu.cn }}$

doi: $10.20964 / 2019.04 .27$

Received: 3 December 2018 / Accepted: 21 January 2019 / Published: 10 March 2019

An electrochemically reduced graphene oxide modified glassy carbon electrode (ERGO/GCE) was synthetized by direct electrochemical reduction of graphite oxide on a glassy carbon electrode (GCE). The prepared ERGO/GCE shows higher sensitivity to eugenol than the bare GCE due to the large surface area and excellent conductivity, indicating that a direct electrochemical behaviour can be significantly enhanced through electrochemically reduced graphene oxide (ERGO) surface modification. The ERGO/GCE displays a fast response time of less than $5 \mathrm{~s}$ and has a detection limit of $5 \times 10^{-7} \mathrm{M}$, covering a linear range from $5 \times 10^{-6} \mathrm{M}$ to $1 \times 10^{-4} \mathrm{M}$. As a result, ERGO nanomaterials have potential applications in sensitive eugenol sensors.

Keywords: Eugenol; ERGO; Direct electrochemistry; Sensor

\section{$\underline{\text { FULL TEXT }}$}

(C) 2019 The Authors. Published by ESG (www.electrochemsci.org). This article is an open access article distributed under the terms and conditions of the Creative Commons Attribution license (http://creativecommons.org/licenses/by/4.0/). 